\title{
The Role of Dimensions of Lexical Repertoire in Reading Comprehension and Incidental Vocabulary Acquisition
}

\author{
Shaban Barimani Varandi \\ Department of English, Science and Research Branch, Islamic Azad University, Mazandaran, Iran \\ Faezeh Faezi \\ Department of English, Science and Research Branch, Islamic Azad University, Mazandaran, Iran
}

\begin{abstract}
The present study was carried out in order to investigate the relationship between dimensions of lexical repertoire, i.e., depth and breadth of lexical knowledge and Iranian EFL learners' incidental vocabulary learning and reading comprehension. The participants of the study were 30 English major students of MA. They were selected from 68 students, based on their performance on Nelson proficiency test. Word Association Test was used to measure students' depth of vocabulary knowledge, Vocabulary Levels Test was administered to examine students' breadth of vocabulary knowledge, MSRT reading test was used to measure their reading comprehension, and Vocabulary Knowledge Scale test was given to test their incidental vocabulary learning. The results of Pearson correlations indicated that there is a significant relationship between both depth and breadth of vocabulary knowledge and EFL learners' incidental vocabulary learning as well as their reading comprehension.
\end{abstract}

Index Terms - lexical repertoire, breadth and depth of vocabulary knowledge, incidental vocabulary learning, reading comprehension

\section{INTRODUCTION}

There is no doubt that vocabulary is very important part of every language and without a reasonable amount of lexical knowledge a good communication cannot take place and comprehension would be difficult. Ellis (1994) believed that lexical errors slow down communication more than grammatical errors. Also, reading as one of the macro skills is a very important variable for EFL students. Having a good command of vocabulary knowledge can help learners to understand a text to a great extent, whether this reading is in form of extensive reading (reading for pleasure) or intensive reading (classroom reading). As an example Anderson and Freebody (1981) declared that teaching vocabulary to students can improve their reading comprehension.

Second language vocabulary learning is generally divided between incidental and intentional vocabulary learning. Hulstijn (2011) believes that Incidental learning is the acquisition of a word or phrase with no conscious intent to memorize the vocabulary, such as "picking up" an unknown word from listening to someone or from reading a text. He indicates that people pick up names, words, dates and events without effort especially when these events were done in the near past. On the contrary, he believes that intentional learning is a deliberate attempt to carry realistic information to memory, usually things like rehearsal techniques or getting ready for a test in school. As there are many words in both the mother tongue and L2, it is not possible to teach all the vocabularies through direct teaching (Nagy, Herman \& Anderson, 1987). Here the role of incidental learning becomes highlighted. Incidental vocabulary learning happens when there is no direct focus on learning itself and getting the message is the main concern (Hulstijn, 2001). Explicit and intentional vocabulary learning happens when learners' awareness is on learning new words (Nation, 2001). The term by-product is labeled by Huckin and Coady (1999) for incidental learning. It should be paid attention that incidental learning should not be confused with unconscious learning; it is just that incidental learning does not require an explicit learning intention (Ellis, 1994). On the other hand Hulstijn (2001) claims that in both types of teaching vocabulary, some amount of attention is required. He believes that when the subjects in intentional learning are told that they would have a test, they will try to set their memory according to the test that they are going to have, but in contrast to this situation, in incidental learning the participants would process the material so their mind will probably not be ready for a productive test, but they would be successful in a receptive test.

The structure of a word is multilayered natured and it engages network building in mental lexicon (Haastrup \& Henrikson, 2000) which involves two dimensions of depth and breadth of vocabulary knowledge (Nassaji, 2004; Nation, 2001; Qian, 1999). Many researchers have noticed that word repertoire is more than just single dimension knowledge. As Vermeer (2001) indicates, the words are like nods in a network. These nods are interrelated in different dimensions: Thematically (table-chair), phonologically (table-label), sociologically, morphologically (gratitude-altitude) and conceptually (cup-mug). As much as the learner makes his/her network bigger, his/her word knowledge will be better. 
This knowledge can be called depth of vocabulary (Nagy \& Herman, 1887 cited in Vermeer, 2001). Also Cronbach (1946, cited in Nation, 2001) mentioned that lexical components can have many aspects such as morpho-syntactic properties, association, derivation, frequency and semantic features. Henrikson (1999) believes that lexical knowledge has three dimensions: 1- precision of knowledge, 2- depth of knowledge, 3- receptive and productive knowledge. In research on vocabulary knowledge; however, two dimensions of depth and breadth of vocabulary are distinctive (Nassaji, 2004; Nation, 2001; Qian, 1999, Paribakht \& Wesche, 1996).

Breadth refers to number of words a learner knows. Nation (2001) believes that breadth of vocabulary knowledge means the quantity or number of words a student knows at a particular level of proficiency. Depth refers to the quality and the amount a learners knows a particular word (Meara, 1996; Read, 1993). Nation (2001) broadens depth by adding pronunciation, collocations, frequency, grammar and spelling. Read (1993) states that depth is a matter of degree and involves the quality of learners' vocabulary knowledge, in other words: how well a student knows a particular vocabulary.

Haastrup and Henrikson (2000) indicate that depth or quality of word knowledge is made by a network that the learners provide by using three relationships that are presented among words: 1- paradigmatic (synonyms), 2syntagmatic (collocation), 3- analytic (meaning). Grabe (1991) indicates that vocabulary enhancement is very important predictor in reading comprehension. Grabe and Stroller (2002) believe that a large amount of lexical knowledge helps in reading comprehension. And if the learners know a large number of words they can be successful readers. They advice the teachers to help the learners through reading by highlighting the key words and explaining them.

A theory proposed by Sternberg and Powell (1983) says that vocabulary learning through reading has three main elements: a) the process of acquisition that learners are involved in, b) contextual cues for example spatial, temporal and etc, c) moderating variables such as the importance of new vocabulary to be understood in the context, density of the words and number of occurrence of the new unknown vocabulary. Three simple principles are suggested in acquiring vocabulary through reading: 1) selective encoding (to divide related information from unrelated information, 2) selective comparison (relating old information to the new information that are stored in memory, 3) selective combination (to gather the related cues to reach organized definition).

In Sternberg and Powell's (1983) point of view the features such as frequency of a new word, the variability of the unknown word which is embedded in the context, the surrounding context, density of the new word and its importance, makes the process of recognizing and learning the unknown word easier or harder. De Bot, Paribakht and Wesche (1997) described three self reported data of: immediate retrospective, delayed retrospective and introspective protocols to show the source that students use in lexical inferencing process and to demonstrate the way they get the meaning of the new vocabulary in the context. They tried to see how learners can acquire new vocabularies from the context without direct instructions. They believe that when the learners encounter a new word, they could be afraid to continue the communication and go on, or they would fail to get information from a reading. De Bot et al. (1997) declare that there are some levels of lexical entry that include semantic and syntactic information about a specific word and at every level a certain amount of information needs to be used to go to the next level and infer the meaning of an unknown word. This syntactic and semantic information can be inferred from the context.

\section{Statement OF THE PROBLEM}

Although a large number of studies acknowledged the significant impact of reading on vocabulary acquisition (Hulstijn, 2001; Krashen, 1989; Nation, 2001; Nation \& Coady, 1988), no clear method was demonstrated for teaching and learning vocabulary. One of the problems is that evaluating lexical repertoire is a hard task (Cronbach, 1942, cited in Nation, 2001).

Although it has been claimed that intentional vocabulary learning outweighs incidental vocabulary acquisition, various researchers have come up with different results under specific conditions with second language learners. Further, previous studies have shown that learners' vocabulary size and word frequency are two crucial factors that affect vocabulary learning. For this reason, in order to determine the effects of these two variables and to make a distinction between the incidental and intentional vocabulary learning, the present study has tried to investigate the effects of two different dimensions of vocabulary knowledge through reading on learners' incidental vocabulary learning. So far, it has not been clear whether applying these learning situations in the Iranian EFL (English as a Foreign Language) classes would be a failure or success.

Of course, the topic of lexical repertoire is a relatively new research area in Iran, especially in the domain of reading comprehension. This needs to be taken into account by Iranian teachers, because their students need to continue learning foreign languages and should be aware of their learning approaches. Thus, the teachers should consider these various learning situations as part of their instruction, so that they can play a valuable and active role in guiding and helping the students to become successful in their learning targets. Finally, research on these language learning approaches of Iranian students should not only provide teachers and students with practical and helpful information about the use of these approaches but also encourage them to develop their images of learning in their minds and know how they act in different situations.

\section{RESEARCH QUESTIONS}


This study intended to investigate the relationship between dimensions of lexical repertoire on Iranian EFL learners' incidental vocabulary learning and reading comprehension. The following research questions were proposed in order to achieve the purpose of the study:

1. Is there any significant relationship between depth and breadth of word knowledge and incidental vocabulary learning of Iranian EFL learners?

2. Is there any significant relationship between depth and breadth of word knowledge and reading comprehension of Iranian EFL learners?

\section{RESEARCH HYPOTHESES}

To answer the above question, the following null hypothesis was formulated:

1. Depth and breadth of word knowledge do not have any significant relationship with Iranian EFL learners' incidental vocabulary learning.

2. Depth and breadth of word knowledge do not have any significant relationship with Iranian EFL learners' reading comprehension.

\section{METHOD}

\section{A. Participants}

A test of proficiency (Nelson test) was given to 68 female graduated students of Islamic Azad University, Central Tehran Branch, based on convenience sampling, to homogenize the advanced students. Forty five students were qualified to take part in this study. To lower the effect of world knowledge and knowledge of academic subject on participants' performance in reading comprehension, the subjects were chosen from a similar educational level and academic major. Unfortunately some refrained from participating in the study due to personal reasons in the middle of the research and some of them were considered as outliers by the researcher as they knew German language based on the demographic form which was embedded at the beginning of the proficiency test. As a result 30 participants remained to take part in the study. All the participants were female and native speakers of Farsi which is a very different language from English and German languages and none of them had ever lived in English or German speaking countries. As a result none of the participants could use their native language for guessing and inferring the meaning of an unknown vocabulary.

\section{B. Materials}

This study utilized the following materials. It consisted of a breadth of vocabulary knowledge test, depth of vocabulary knowledge test, vocabulary knowledge scale and a reading comprehension test.

\section{Breadth of Vocabulary Knowledge Test}

The vocabulary size test which is used in this research is a revised version of Vocabulary Levels Tests (Schmitt, Schmitt, \& Clapham, 2001). The expanded test has two versions which the authors of the test believe that the version 1 and 2 have no difference in terms of quality and difficulty. The researcher of the current study used the second version of this test which contained five different levels: 2000 words level, 3000 words level, 5000 words level, 10000 words level and an academic part. Each level contains 10 parts with six words and three definitions, which means three correct answers (matched words and short definitions). The subjects were asked to match the three definitions with three of the six words for any item at each cluster. Each level has 60 words and 30 definitions. Each correct answer is awarded one point so the whole test will have 150 correct answers. In the present study, the researcher used all the levels of the test. The time required to finish this test as other authors have mentioned is about 31 minutes for each version of the test in a valid study. The participants were given a short instruction with examples before taking the test. The breadth test took about 30-45 minutes for this study.

\section{Depth of Vocabulary Knowledge Test}

Word Association Test (WAT) (Read, 2004) was chosen to be administered in this section. The format of the test contains 40 items with multiple choices. Each item has one vocabulary as test stem, four options on the left side and four options on the right side. The left column has the potential to be chosen as the meaning of the stem and the right column has the potential to be associated with the stem vocabulary. The four words in left are adjectives which can be either synonym with the word above or can have a polysemy relationship with the stimulus word. The words in the right column can collocate with the stimulus word. The correct choices are not evenly spread; as a result there can be these situations as correct answers: each left and right column contains 2 correct answers, the right column contains three correct answers and left column contains 1 correct answer, the right column contains one correct answer and the left column contains three correct answers (three situations). As the format of the test is not self explanatory, some instructions along with examples were provided for the participants to show them how to choose the correct answers.

The participants should choose four options for each vocabulary in the stem; the answers were distributed in the 8 options. Each correct answer was awarded one point so all the correct answers have the sum of 160. The test is based on word association and includes three parts of paradigmatic (meaning), syntagmatic (collocation), and lexical progression (process of lexical building). Version 4 of this test was used for this study. The depth test took about 43-55 minutes. 


\section{Vocabulary Knowledge Scale}

In order to measure incidental vocabulary learning, a Vocabulary Knowledge Scale (VKS) Test (Paribakht \& Wesche, 1997) was administrated. This test can have a repeated measure design to see the retention of the subjects during different periods of time. Also this test has a standard nature to measure initial vocabulary knowledge (Paribakht $\&$ Wesche, 1996). The test has 5 options and the participant should choose one of the options for each inferred vocabulary. These five questions are combination of self report and performance to show the vocabulary knowledge of the test takers in written format. The range starts from total unfamiliarity, recognition, having some ideas about that vocabulary to using that word in a sentence grammatically and semantically correct. The scoring of the test for option 1 is one score, for option 2 is two scores and for options 3 and 4 is three, the score four goes for the learner who has figured the meaning of the vocabulary correctly in the sentence but has not figured the correct grammatical category, and finally score 5 is devoted for using the word correctly in a sentence both in terms of meaning and grammar. It should be noted that wrong answers for options 3, 4 and 5 would have the gain score of two. The researcher decided to use all 5 categories in her research, as the first two categories reveal the receptive knowledge of the participants, the middle option is to show if the subject has any idea of the meaning in target form and the last two categories show the total productivity knowledge of the inferred target word.

\section{Reading Comprehension test}

The reading comprehension test chosen for the present study was ministry of science and research and technology (MSRT) reading comprehension test. This test is designed to measure the English proficiency of non-native speakers of English in Iran and also it is necessary for male students who would like to study abroad. The MSRT test is in paper format and contains the following parts: Listening comprehension, structure and written expression and reading comprehension. The researcher of this study chose three reading parts of MSRT test based on the purpose of this study. The participants had to answer the multiple choices questions based on the readings. The test is available on (http://www.test4u.webs.com/).

\section{Procedures}

In order to answer the research questions after administering the proficiency test and gathering the participants, the researcher gave the four main tests of breadth of vocabulary knowledge, depth of vocabulary knowledge, reading comprehension and the Vocabulary Knowledge Scale test and collected all the scores. Each participant was given a file which contained all her scores. As the tests were administered in various orders, the researcher waited until all the data were gathered (during February \& April 2013). There was no doubt that the scoring would be subjective due to variety of reasons. As a result to find out that the meaning of the target words were marked correctly; whether they were truly in grammatical or semantic group or whether the written words were truly a synonym or translation of that word, the researcher asked a colleague of hers who had an MA degree to mark some of the papers again (about $25 \%$ of the papers). The researcher collected the two sets of scores and compared them. As the whole procedure was explained to her and she was totally involved in this study based on a mutual understanding between the two raters for marking the papers, an inter-rater reliability of $94 \%$ was found between the two sets of scores.

The collected data were in form of paper and pencil. The tests included a proficiency test, depth of vocabulary knowledge, breadth of vocabulary knowledge and Vocabulary Knowledge Scale test. At the beginning of each test a written instruction was added, but in order for the participants not to misunderstand any of the items, the researcher explained the instruction in Farsi before each administration. As an example they were asked to infer the meanings of target words which were in German language, in English or Farsi based on the 5 options of VKS test and to write the meanings on the separate sheet available for them.

To lower the order effect the researcher took the main test in different orders. Another factor which would affect the test was the fatigue factor (usually due to tiredness participants do less in their last exam) which by varying the orders of the test it would have its least effete. The distribution of tests was randomly done using random identification code which was assigned to each of the test takers. The participants were divided into 5 groups and each group took one of the below test models:

1- Depth, reading comprehension, VKS, breadth

2- Reading comprehension, VKS, depth, breadth

3- Breadth, depth, reading comprehension, VKS

4- Breadth, reading comprehension, VKS, depth

5- Depth, breadth, reading comprehension, VKS

To make the situation of the test incidental, the researcher asked the participants to read the short story in a way to enjoy it. The test takers did not have any idea that the target words were in German language, and the researcher refrained from answering their questions about nature of the words. The participants were free to finish the tests at the time they wanted and there was no time limitation. They even could have a short break after finishing each test and then go on with another test. The short story took about 20-40 minutes to read but most of the participants finished it in about 30 minutes. The VKS test took about 8-14 minutes to be completed. 
Nelson was administered to 68 advanced EFL learners at the beginning of study. Considering the obtained scores in Table 1, too distant scores from below and above the mean were omitted in order to homogenize the participants regarding their level of language proficiency. In this case, the participants who scored within a range of one standard deviation below (65) and above the mean (84) kept in the study. So, 23 learners were excluded from the main study. The descriptive statistics of selected scores are shown in Table 1. The mean is 75.11, and the degree of skewness and kurtosis and standard deviation indicate that the distribution of scores is normal.

TABLE 1.

DESCRIPTIVE STATISTICS OF HOMOGENIZED PARTICIPANTS

\begin{tabular}{|c|c|c|c|c|c|c|c|c|c|}
\hline & $\mathrm{N}$ & Minimum & Maximum & Mean & Std. Deviation & Skewness & & Kurtosis & \\
\hline & Statistic & Statistic & Statistic & Statistic & Statistic & Statistic & Std. Error & Statistic & Std. Error \\
\hline $\begin{array}{l}\text { Nelson Test } \\
\text { (Homogenized) }\end{array}$ & 45 & 65 & 84 & 75.11 & 6.569 & -.145 & .354 & -1.495 & .695 \\
\hline
\end{tabular}

The descriptive statistics related to the scores of the participants on the tests of depth and breadth of vocabulary knowledge is presented in Table 2.

TABLE 2.

DESCRIPTIVE STATISTICS OF THE OBTAINED SCORES ON DEPTH AND BREADTH OF VOCABULARY KNOWLEDGE TESTS

\begin{tabular}{|llllll|}
\hline & $\mathrm{N}$ & Minimum & Maximum & Mean & Std. Deviation \\
\hline Breadth of Vocabulary Knowledge & 30 & 128 & 150 & 139.87 & 5.859 \\
\hline Depth of Vocabulary Knowledge & 30 & 110 & 147 & 130.10 & 10.739 \\
\hline
\end{tabular}

On the other hand, EFL learners' incidental vocabulary learning was measured by means of Vocabulary Knowledge Scale (VKS) tests. In order to verify the relationship between depth and breadth of EFL learners' vocabulary knowledge on their incidental vocabulary learning, Pearson correlation coefficient was performed.

TABLE 3.

CORRELATIONS BETWEEN DEPTH AND BREADTH AND INCIDENTAL VOCABULARY LEARNING

\begin{tabular}{|c|c|c|c|c|}
\hline & & $\begin{array}{l}\text { Breadth of Vocabulary } \\
\text { Knowledge }\end{array}$ & $\begin{array}{l}\text { Depth of Vocabulary } \\
\text { Knowledge }\end{array}$ & VKS Score \\
\hline \multirow{3}{*}{ Breadth of Vocabulary Knowledge } & Pearson Correlation & 1 & $.872^{* *}$ & $.685^{* *}$ \\
\hline & Sig. (2-tailed) & & .000 & .000 \\
\hline & $\mathrm{N}$ & 30 & 30 & 30 \\
\hline \multirow{3}{*}{ Depth of Vocabulary Knowledge } & Pearson Correlation & $.872^{* *}$ & 1 & $.526^{* *}$ \\
\hline & Sig. (2-tailed) & .000 & & .002 \\
\hline & $\mathrm{N}$ & 30 & 30 & 30 \\
\hline
\end{tabular}

The results, as shown in Table 3, indicated that there is a significant relationship between the depth $(\mathrm{r}=.52, \mathrm{p}<.01)$ and breadth $(r=.68, p<.01)$ of vocabulary knowledge and incidental vocabulary learning. Therefore, depth and breadth of Iranian EFL learners' vocabulary knowledge have a significant relationship with their incidental vocabulary learning. Table 3 also shows that there is a significant relationship between depth and breadth of vocabulary knowledge $(r=.87, p<.01)$. Thus, the first null hypothesis of this study saying depth and breadth of word knowledge do not have any significant relationship with Iranian EFL learners' incidental vocabulary learning is not accepted.

The second research hypothesis investigates the impact of depth and breadth of vocabulary knowledge on EFL learners' reading comprehension. The descriptive statistics related to the scores of the participants on reading comprehension is shown in Table 4.

TABLE 4.

DESCRIPTIVE STATISTICS OF EFL LEARNERS' SCORES ON READING COMPREHENSION TEST

\begin{tabular}{llllll}
\multicolumn{6}{c}{ DESCRIPTIVE STATISTICS OF EFL LEARNERS } \\
\hline & $\mathrm{N}$ & Minimum & Maximum & Mean & Std. Deviation \\
\hline Reading Comprehension & 30 & 20 & 29 & 24.90 & 1.788 \\
\hline
\end{tabular}

In order to verify the second research question of this study, Pearson correlation coefficient was run.

TABLE 5.

CORRELATIONS BETWEEN DEPTH AND BREADTH AND READING COMPREHENSION

\begin{tabular}{|c|c|c|c|c|}
\hline & & $\begin{array}{l}\text { Breadth of Vocabulary } \\
\text { Knowledge }\end{array}$ & $\begin{array}{l}\text { Depth of Vocabulary } \\
\text { Knowledge }\end{array}$ & $\begin{array}{l}\text { Reading } \\
\text { Comprehension }\end{array}$ \\
\hline \multirow{2}{*}{$\begin{array}{l}\text { Breadth of Vocabulary } \\
\text { Knowledge }\end{array}$} & Pearson Correlation & 1 & $.872^{* * *}$ & $.855^{* *}$ \\
\hline & Sig. (2-tailed) & & .000 & .000 \\
\hline \multirow{2}{*}{$\begin{array}{l}\text { Depth of Vocabulary } \\
\text { Knowledge }\end{array}$} & Pearson Correlation & $.872^{* *}$ & 1 & $.726^{* *}$ \\
\hline & Sig. (2-tailed) & .000 & & .000 \\
\hline
\end{tabular}


According to Table 5, there is a significant relationship between depth $(r=.72, p<.01)$ and breadth $(r=.85, p<.01)$ of vocabulary knowledge and Iranian EFL learners' reading comprehension ability. Therefore, depth and breadth of vocabulary knowledge of Iranian EFL learners have a significant relationship with their reading comprehension. Hence, the second null hypothesis of this study stating depth and Breadth of word knowledge do not have any significant relationship with Iranian EFL learners' reading comprehension is statistically not accepted.

\section{DISCUSSION}

The present study was developed in order to pursue three main purposes; to measure the relationship between EFL learners' depth and breadth of vocabulary knowledge and their incidental vocabulary learning, to examine the relationship between depth and breadth of vocabulary knowledge and reading comprehension and to find the stronger dimension of lexical repertoire in predicting incidental vocabulary learning and reading comprehension of EFL learners.

In order to investigate the above-mentioned purposes a structured procedure consisting of 68 Iranian MA students majoring Teaching English as a Foreign Language (TEFL) was developed. The participants of the study took standardized Nelson test in order to manifest their homogeneity in terms of their level of language proficiency. Based on the obtained data, 30 students were selected for the main study.

The first hypothesis of the study was pursued the relationship between depth and breadth of vocabulary knowledge and incidental vocabulary learning among Iranian EFL students. The results of correlation analysis showed that there is a significant relationship between both depth and breadth of vocabulary knowledge and EFL learners' incidental vocabulary learning. In other words, students who had higher depth and breadth of vocabulary knowledge achieved greater incidental vocabulary learning. Also, a significant relationship was found between depth and breadth of vocabulary knowledge. These findings supported the findings of Vermeer (2001) and Nassaji (2004) in that higher levels of depth and breadth vocabulary knowledge lead to higher degrees of vocabulary learning. The significant relationship between depth and breadth of vocabulary knowledge that was found in this study was in line with what Nurweni and Read (1999) had found in their study.

The second research hypothesis investigates the impact of depth and breadth of vocabulary knowledge on Iranian EFL learners' reading comprehension. The results of Pearson correlation showed that there is also a significant relationship between depth and breadth of vocabulary knowledge and reading comprehension of EFL learners. The second null hypothesis of this study was not accepted. This finding is consistent with the Huang (1999) who found that learners' comprehension of reading texts was significantly dependent on their vocabulary knowledge. High relationship between depth and breadth of vocabulary knowledge and reading comprehension was also found in Qian's (1999) study on Chinese and Korean EFL learners. Similar findings were also found in Qian's (2002) research of the relationship between vocabulary knowledge and academic reading. Hence, using a mixture of words in both depth and breadth results in a better capability to predict reading performance. The result of analysis on second hypothesis of the study confirmed Zhang and Annual's (2008) findings. They found that the better the learners were at breadth of vocabulary knowledge the better they could perform at reading comprehension. In Iran, this finding was in line with Kavianpanah and Zandi's (2009) study on the role of depth of vocabulary knowledge in reading comprehension of male and female EFL learners.

\section{IMPLICATIONS}

The findings of this study provided some valuable insights and implications for vocabulary learning and teaching in EFL contexts. In this part, the theoretical and pedagogical implications of study are described.

From a theoretical point of view, this study represented dimensions of lexical repertoire, i.e., depth and breadth of lexical knowledge, as the effective and interesting ways for improving vocabulary knowledge and reading comprehension ability of language learners. It also provided the best conditions for learners to learn lexical items deeply and to extend their knowledge of vocabulary.

The significance of dimensions of lexical repertoire in developing vocabulary knowledge and reading comprehension, from a pedagogical point of view, showed helpful approaches for EFL teachers, EFL learners and syllabus designers.

EFL teachers can use the depth and breadth of vocabulary knowledge to make sure that their learners would have the least forgetting process in vocabulary acquisition. There is no doubt that without the teachers' guidance learning the lexical items would not be easy. The teacher should help the learners to understand the nature of each vocabulary and learn each lexical item in the related context and not just by itself. S/he should be creative enough to invent new methods for teaching vocabulary specially by using these two dimensions of lexical repertoire. In this regard Allen (1983) believes that old fashioned methods for vocabulary learning would only be time consuming.

For EFL teachers, the results of this study provide valuable opportunities to engage learners in vocabulary learning process. In EFL contexts, since there is no opportunity to be exposed to language out of classroom situation, it seems necessary to provide conditions for learners in order to take the maximum advantages of class time. Vocabulary instruction by conscious attention to the dimensions of lexical repertoire invites learners to deeply process the lexical items. Learners can analyze the vocabularies and realize the advantages of such methods over the old methods like making a list of vocabularies in both L1 and L2 and trying to memorize them two by two. 


\section{SUGgestions FOR FurTher RESEARCH}

In this section, some suggestions are suggested for future studies, based on the limitations of the research and the problems that the researcher viewed through the study.

The participants of this study were advanced EFL learners. Another study can study the effect of lexical repertoire in vocabulary learning or reading comprehension of learners of other levels of language proficiency.

The present study investigated the relationship between learners' depth and breadth of vocabulary knowledge and reading comprehension. It is suggested for further studies to investigate the effectiveness of learners' depth and breadth of vocabulary knowledge on other language skills such as speaking, reading and writing.

A short story with 10 target words was chosen for this research. Obviously, more target words in a longer context would strengthen the result. Although the researcher has used different word class with repeated frequencies in the selected text, she did not focus deeply on these two aspects as they were not part of her study.

\section{REFERENCES}

[1] Allen, V. F. (1983). Techniques in teaching vocabulary. Oxford: Oxford University Press.

[2] Anderson R. C. \& Freebody, P. (1981). Vocabulary knowledge. In J. T. Guthrie (Ed.), Comprehension and Teaching: Research Perspectives. Newark, DE: International Reading Association.

[3] De Bot, K., Paribakht, S., \& Wesche, M. (1997). Toward a lexical processing model for the study of second language vocabulary acquisition. SSLA, 19, 309-329.

[4] Ellis, N. (1994). Introduction: Implicit and explicit language learning - an overview. In Ellis, N. (ed.). Implicit and explicit learning of languages. Academic Press: Hertfordshire.

[5] Grabe, W. (1991). Current developments in second language reading research. TESOL Quarterly, 25, 375-406.

[6] Grabe, W., \& Stoller, F. L. (2002). Teaching and researching reading. Harlow: Longman.

[7] Haastrup, K., \& Henrikson, B. (2000). Vocabulary acquisition: acquiring depth of knowledge through network building. International Journal of Applied Linguistic, 10,221-240.

[8] Henrikson, B. (1999). Three dimensions of vocabulary development. SSLA, 21, 303-318.

[9] Huang, C. (1999). The effects of vocabulary knowledge and prior knowledge on reading comprehension of EFL students in Taiwan. Retrieved August 10, 2013 from http://contentdm.lib.byu.edu/ETD/image/etd2508.pdf.

[10] Huckin, T., \& Coady, J. (1999). Incidental vocabulary acquisition in a second language: A review. Studies in Second Language Acquisition, 21, 181-193.

[11] Hulstijn, J. H. (2001). Intentional and incidental second language vocabulary learning: A reappraisal of elaboration, rehears al, and automaticity, in Robinson, P. (ed.), Cognition and Second Language Instruction. Cambridge: Cambridge University Press.

[12] Hulstijn, J. H. (2011). Explanations of associations between L1 and L2 literacy skills. In M.S. Schmid \& W. Lowie (Eds.), Modeling bilingualism: from structure to chaos: in honor of Kees de Bot (Studies in bilingualism, 43) (pp. 85-111). Amsterdam: Benjamins.

[13] Kaivanpanah, S., \& Zandi, H. (2009). The role of depth of vocabulary knowledge in reading comprehension in EFL context. Journal of Applied Sciences, 9(4), 698-706.

[14] Krashen, S. (1989). We acquire vocabulary and spelling by reading: Additional evidence for the input hypothesis. Modern Language Journal, 73, 445-464.

[15] Meara, P. (1996). The dimensions of lexical competence. In G. Brown., K. Malmkjaer, and J. Williams (Eds). Performance and Competence in Second Language Acquisition (35-53). Cambridge: CUP.

[16] Mondria, J. \& Wit-De Boer, M. (1991). The effects of contextual richness on the guessability and the retention of words in a foreign language. Applied Linguistics, 12, 249-2670.

[17] Nagy, W., Herman., R. C., \& Anderson, A. (1987). Incidental acquisition of word meaning from expositions with varied text features. Reading Research Quarterly, 24, 263-289.

[18] Nassaji, H. (2004). The relationship between depth of vocabulary knowledge and L2 learners' lexical inferencing strategy use and success. Canadian Modern Language Review, 61, 107-134.

[19] Nation, I. S. P. (2001). Learning vocabulary in another language. Cambridge, England: Cambridge University Press.

[20] Nation, I. S. P., \& Coady, J. (1988). Vocabulary and reading. In R. Carter \& M. McCarthy (Eds.), Vocabulary and language teaching. London: Longman.

[21] Nurweni, B. \& Read, J. (1999). The English vocabulary knowledge of Indonesian university students. English for Specific Purposes, 18, 161-175.

[22] Paribakht, T. S., \& Wesche, M. (1996). Enhancing vocabulary acquisition through reading: a hierarchy of text-related exercise type. The Canadian Modern Language Review, 52, 155-178.

[23] Paribakht, S. \& Wesche, M. (1997). Vocabulary enhancement activities and reading for meaning in second language vocabulary development. In Coady and Huckin (Eds.), second language vocabulary acquisition: A rationale for pedagogy (pp. 147-200). Norwood, NJ: Ablex.

[24] Paribakht, T. S., \& Wesche, M. (1999). Reading and incidental L2 vocabulary acquisition. Studies in Second Language Acquisition, 21, 195-224.

[25] Qian, D. D. (1999). Assessing the roles of depth and breadth of vocabulary knowledge in reading comprehension. Canadian Modern Language Review, 56, 282-307.

[26] Qian, D. D. (2002). Investigating the relationship between vocabulary knowledge and academic reading comprehension. Language Learning, 52, 513-536.

[27] Read, J. (1993). The development of a new measure of L2 vocabulary knowledge. Language Testing, 10, 355-371.

[28] Read, J. (2004). Plumbing the depths: how should the construct of vocabulary knowledge be defined. In Bogaards, P., Laufer, B. (Eds.), Vocabulary in a Second Language (pp. 209-227). Amsterdam: John Benjamins Publishing Company. 
[29] Schmitt, N., \& Schmitt, D., \& Clapham, C. (2001). Developing and exploring the behavior of two new versions of the vocabulary levels test. Language Testing, 18, 55-88.

[30] Sternberg, R. \& Powell, S. (1983). Comprehending verbal comprehension. American Psychologist, 38, 878-893.

[31] Vermeer, A., (2001). Breadth and depth of vocabulary in relation to L1/L2 acquisition and frequency of input. Applied Psycholinguistics, 22, 217- 234.

[32] Zhang, L. J. \& Annual, S. B. (2008). The role of vocabulary in reading comprehension. RELC, 39, 51-76.

Shaban Barimani Varandi was born in Iran in 1956. He received a Ph.D. in TEFL (Teaching English as a Foreign Language) from Mysore University in 2009 in India, an M.A. in TEFL from Islamic Azad University in Iran, in 2001, and a B.A. in TEFL from UTE (University for Teacher Education) in Tehran, Iran in 1989.

As for his professional background, he is the chairman of the EFL department at Islamic Azad University, Sari Branch since 2009 up to now and a member of the faculty member of English Language and Linguistics in Islamic Azad University, Sari Branch since 2002. Now, as chairman in TEFL and Linguistics and as an associate professor, he runs courses in Linguistics, Research, Testing, and methodology in Sari and Mazandaran Science \& Research branches of Islamic Azad University at the levels of BA and MA.

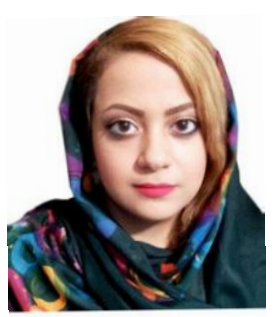

Faezeh Faezi is an English, Arabic and German teacher at different institutes. She got her MA in TEFL from Islamic Azad University, Mazandaran Science and Research Branch-Iran and her BA in German translation in Tehran University. She has attended different workshops, sessions and conferences in the related fields and she currently works at education department of ISESCO regional office in Tehran. 